\title{
TOXIC EFFECT OF CHLORPYRIFOS PESTICIDES ON THE BEHAVIOUR AND SERUM BIOCHEMISTRY OF HETEROPNETUES FOSSILIS (BLOCH)
}

\author{
Sadguru Prakash \\ Department of Zoology, M.L.K.(P.G.) College, Balrampur (U.P.)
}

Received: 17.05.2020

Revised: 22.05.2020

Accepted: 05.06.2020

\begin{abstract}
The present investigation has been designed to study the effect of sublethal concentrations of Chlorpyrifos on the behavior and serum biomolecules of Heteropnetues fossilis (Bloch) after exposure to 96 hours. The present study shows that behavioural alterations such as alternation in opercular movements, surfacing, swimming, jumping, and mucous secretion. Serum biomolecules such as glucose, protein, triglyceride, cholesterol and urea were significantly increased in Chlorpyrifos exposed fish. The response of the fish towards toxicity of chlorpyrifos was grossly dependent on concentration and length of exposure. Thus, this paper gives an overview of the manipulation of fish, Heteropnetues fossilis as a biomarker of pesticides through alternation in behavior and biochemical parameters.
\end{abstract}

Keywords: Behavior, Chlorpyrifos, Heteropnetues fossilis, Serum Biomolecules.

\section{INTRODUCTION}

Pesticides include a wide variety of chemicals with great difference in their mode of action, uptake by the body, metabolism and elimination from the body and toxicity to target and non-target organisms. The widespread use of pesticides not only brought adverse influence on agro ecosystems but also caused alteration in physiological processes of non-target organisms. These pesticides through surface runoff reaches into the waterbodies like ponds and rivers which alters the physicochemical properties of water and is toxic to aquatic organism and cause deleterious effect or even death to the aquatic animals. Poisoning risks depend on dose, toxicity, duration of exposure and sensitivity. Application of organophosphorus insecticides in crop field has a great impact on aquatic system especially on fish population. In spite of terrible impact of pesticide on aquatic environment, it is vastly used in agricultural sector (Kadam and Patil, 2016). These pesticides enter the food chain and their subsequent bioaccumulation and biotransformation at different trophic levels have catastrophic effect to the ecosystem (Grande et al., 1994).

During the last two decade a tremendous progress has been made in the development of new compounds with better toxicity, therefore, a lot of work has been carried out on impact of pesticides on non-target aquatic organisms. Organophosphates are highly toxic to fish and non-target aquatic organisms and are powerful nerve poisons, since they inhibit AChE activity (Klaverkamp and Hobden, 1980).

Chlorpyrifos, a broad spectrum organophorous insecticide used against pod borers, fruit borers, stem borers, leaf miners, defoliating caterpillars, sucking pests, termites etc and in other settings, to kill a number of pests, including insects and worms. It acts on the nervous systems of insects by inhibiting the acetylcholinesterase enzyme. Chlorpyrifos is considered moderately hazardous to

*Corresponding author: *sadguruprakash@gmail.com 
humans by the World Health Organization based on its acute toxicity (WHO, 2010). It enters into the aquatic ecosystem and affects aquatic organism (Chernyak et al., 1996; Livingstone, 2001). Poisoning from chlorpyrifos may affect the central nervous system, the cardiovascular system, and the respiratory system as well as a skin and eye irritant of fish (Cox, 1994; 1995).

The toxicity study is essential to find out toxicants limit and safe concentration, so that there will be minimum harm to aquatic fauna in the near future. Tiwari et al., (2019) also conducted similar studies in plants. Among the several aspects of toxicity studies, the bioassay constitutes one of the most commonly used methods in aquatic environmental studies with suitable organisms. The necessity of determining the toxicity of substances to commercially aquatic forms at the lower level of the food chain has been useful and accepted for water quality management (Zahan et al., 2019).

The fishes, best indicator of water body pollution, are the most sensitive of all aquatic animals. Fish is an important source of protein and easily digestible food for human being. It plays a vital role to fulfill our nutritional requirement. However, now a days due to different natural and anthropogenic activities, fish production in natural waterbodies are declined due to unexpected temperature variation, unfavorable $\mathrm{pH}$, dissolved oxygen, dissolved solids, application of pesticides and biological agents like parasites, bacteria, virus, fungus etc. are the main causes of declining the fish population (Siddiqa et al., 2016). In many countries, large scale mortality of fishes has been recorded due to pesticides in water bodies as pollutants (Nikam, 2011). Biochemicals are the most assessable body contents for checking the toxicity of any chemicals. Any alternation in biochemical parameters can result in serious outcomes in the form of various diseases in both the animal and its consumers.
Several studies have been conducted in assessing the toxicity of organophosphorous insecticides on different fish species (Verma et al., 1982; Hoque et al., 2000; Vasit and Patil, 2005; Thenmozhi et al., 2011; Sharmin et al., 2014; Palanikumar et al., 2014; Prakash and Verma, 2014, Verma and Prakash, 2018 and Kadam and Patil, 2016; Kaur and Mishra, 2019). Perusal of literature reveals paucity of information on acute toxicity of Chlorpyrifos on freshwater fishes such as Heteropneutes fossilis which are nutritional and popular fish in the study area. In the present study, an attempt was made to examine the toxic effects of chlorpyrifos on the serum biomolecules of freshwater catfish, $H$. fossilis.

\section{MATERIALS AND METHODS}

The healthy Heteropneutes fossilis ranging from 8.5-9.5 cm in length and 9.0-10.0 g in weight were collected from local fish ponds and washed with $1 \%$ solution of $\mathrm{KMnO}_{4}$ for five minute and then transferred to the plastic jar containing 50L dechlorinated tap water for acclimatization. Fishes were acclimated to laboratory conditions for 10 days at room temperature. The $\mathrm{LC}_{50}$ values of Chlorpyrifos at 96 hours of exposure were estimated to be $23.10 \mathrm{ppm}$ for air breathing catfish, $H$. fossilis $(14.01 \pm 1.03 \mathrm{~cm}$ in size). At $95 \%$ confidence level, the lower and upper limits were 17.46 ppm and 28.74 ppm for $H$. fossili (Zahan et al, 2019). Based on $96 \mathrm{LC}_{50}$, fishes were exposed to sublethal concentrations (5,10 and 15 ppm) for the period of 48, 72 and 96 hours. A control group was maintained in an identical environment. The fishes were regularly fed with commercial food and the medium was changed daily to remove faeces and food remnants. Five fishes from each set were sacrificed for the collection of blood. Blood samples of these fishes were collected from caudal vein in the glass tubes and centrifuged at $3500 \mathrm{rpm}$ for 10 minutes and serum was transferred into eppendorfs. The serum metabolites such as glucose, protein, triglycerides, cholesterol and urea were analysed by Mendel et al., (1954), Lawery's method as Glutamate pyruvate Bergmeyer (1974), Barnes and Blackstock (1973), Warnick (1991) and Pathson and

Table 1: Effects of sublethal concentration of Chlorpyrifos (15ppm) on Behavioural responses of Heteropneustes fossilis at different exposure period of exposure.

\begin{tabular}{|l|c|c|c|c|c|}
\hline $\begin{array}{l}\text { Exposure period } \\
\text { (hrs) }\end{array}$ & Opercular beats & Surfacing & Jumping & Swimming & Mucus secretion \\
\hline 24 & ++ & ++ & ++ & ++ & + \\
\hline 48 & ++ & ++ & + & + & + \\
\hline 72 & ++ & + & - & - & +++ \\
\hline 96 & ++ & + & +++ \\
\hline
\end{tabular}

-=None, + = mild, $++=$ moderate, $+++=$ Slightly higher 
Nauch, (1977), methods, respectively.

\section{RESULTS AND DISCUSSION}

In the present study fish, Heteropneustes fossilis in the control group was found to be active and healthy with normal swimming behaviour. When the fish were exposed to sublethal concentration of Chlorpyrifos (15ppm), they increased their visit to the surface of water and tried to jump out of water. Surface visit of pesticide exposed fishes was found to be moderate for 24 and 48 hours and mild for 72 and 96 hours. The tendency to jump out of the aquarium and swimming were moderate for the first days. From the second day of exposure, fishes showed mild jumping and swimming behavior. After 72 hours the exposed fishes shows no jumping and swimming activities. After 48 hours, mucous secretion on all over the body was slightly increased. The physiological responses recorded during the exposure period were gulping of air and opercular movement. The gulping of air (opercular beet)was slightly higher than control fishes. Increased opercular beat (aquatic breathing) may be due to the physiological adaptation of fish in hypoxic conditions. In fishes, during hypoxic conditions, breathing rate (opercular activity) increases in order to compensate the decreased $\mathrm{pO}_{2}$ level of blood (Srivastava and Prakash, 2018). Increase in surfacing and gulping of surface water appears as an attempt to avoid breathing in the polluted water. As a defense mechanism to neutralize the toxic effect of pollutant, copious amount of mucus is secreted by the fish gradually covers the whole body, gills and buccal cavity (Prakash and Verma, 2019). Thus pesticides altered the whole behavioural activities of fish and making them more susceptible to be preyed reduces their ability to feed, maintain their position and defend their territories.

The pollutants dissolved in water generally disturb the oxygen content of the aquatic environment and found to interfere with aerobic oxidative process involving carbohydrate, protein and lipid metabolisms as revealed by the shift in serum glucose, protein, triglycerides and cholesterol levels (Table.2).

Table 2: Effects of sublethal concentrations of Chlorpyrifos on serum biomolecules of Heteropneustes fossilis at different exposure period of exposure $(\mathrm{N}=5)$.

\begin{tabular}{|c|c|c|c|c|}
\hline \multirow{2}{*}{$\begin{array}{l}\text { Serum Biochemical } \\
\text { Parameters }\end{array}$} & \multirow[t]{2}{*}{ Group } & \multicolumn{3}{|c|}{ Exposure periods in Hours } \\
\hline & & 48 & 72 & 96 \\
\hline \multirow{4}{*}{$\begin{array}{l}\text { Glucose } \\
\text { (mg/dl) }\end{array}$} & Control & $41.05 \pm 0.14$ & $41.74 \pm 0.18$ & $42.15 \pm 0.19$ \\
\hline & $5 \mathrm{ppm}$ & $44.14 \pm 0.24^{*}$ & $46.18 \pm 0.15^{*}$ & $48.58 \pm 0.17 *$ \\
\hline & $10 \mathrm{ppm}$ & $46.24 \pm 0.14 *$ & $48.58 \pm 0.16^{*}$ & $51.14 \pm 0.17 * *$ \\
\hline & $15 \mathrm{ppm}$ & $52.68 \pm 0.15^{* *}$ & $55.11 \pm 0.14^{* *}$ & $58.14 \pm 0.16^{* * *}$ \\
\hline \multirow{4}{*}{$\begin{array}{l}\text { Total Protein } \\
\text { (mg/dl) }\end{array}$} & Control & $75.12 \pm 0.16$ & $75.87 \pm 0.14$ & $76.25 \pm 0.17$ \\
\hline & $5 \mathrm{ppm}$ & $78.14 \pm 1.14 *$ & $81.12 \pm 1.16^{*}$ & $84.25 \pm 1.18^{*}$ \\
\hline & 10ppm & $80.17 \pm 2.10 *$ & $83.25 \pm 1.87 *$ & $84.58 \pm 1.33^{* *}$ \\
\hline & $15 \mathrm{ppm}$ & $82.87 \pm 1.17 *$ & $85.76 \pm 1.49 * *$ & $87.85 \pm 1.58^{* *}$ \\
\hline \multirow{4}{*}{$\begin{array}{l}\text { Triglycerides } \\
\text { (mg/dl) }\end{array}$} & Control & $57.54 \pm 1.11$ & $58.14 \pm 0.87$ & $57.85 \pm 0.54$ \\
\hline & $5 \mathrm{ppm}$ & $61.25 \pm 1.22$ & $64.32 \pm 1.47 *$ & $67.25 \pm 1.54 *$ \\
\hline & 10ppm & $63.58 \pm 1.25^{*}$ & $66.87 \pm 1.42^{*}$ & $69.87 \pm 1.54 * *$ \\
\hline & $15 \mathrm{ppm}$ & $66.21 \pm 1.35^{*}$ & $69.21 \pm 1.14^{* *}$ & $73.35 \pm 1.54 * 8$ \\
\hline \multirow{4}{*}{$\begin{array}{l}\text { Total Cholesterol } \\
\text { (mg/dl) }\end{array}$} & Control & $187.12 \pm 1.21$ & $188.02 \pm 0.97$ & $189.01 \pm 0.57$ \\
\hline & $5 \mathrm{ppm}$ & $191.24 \pm 1.42$ & $193.13 \pm 1.25$ & $195.24 \pm 1.61 *$ \\
\hline & 10ppm & $194.25 \pm 1.16^{*}$ & $196.14 \pm 1.29 *$ & $199.24 \pm 1.34 *$ \\
\hline & $15 \mathrm{ppm}$ & $197.11 \pm 1.51^{*}$ & $199.21 \pm 1.65 *$ & $203.14 \pm 1.17 * *$ \\
\hline \multirow{4}{*}{$\begin{array}{l}\text { Blood Urea } \\
\text { (mg/dl) }\end{array}$} & Control & $3.98 \pm 0.25$ & $4.01 \pm 0.35$ & $4.02 \pm 0.25$ \\
\hline & $5 \mathrm{ppm}$ & $5.11 \pm 0.14$ & $6.21 \pm 0.23^{*}$ & $7.14 \pm 0.38 *$ \\
\hline & $10 \mathrm{ppm}$ & $6.12 \pm 0.17 *$ & $7.38 \pm 0.24^{*}$ & $8.25 \pm 0.41^{* *}$ \\
\hline & $15 \mathrm{ppm}$ & $7.81 \pm 0.51^{*}$ & $8.01 \pm 0.36^{* *}$ & $9.78 \pm 0.44^{* *}$ \\
\hline
\end{tabular}

*Significant at $\mathrm{P}<0.05$; ** significant at $\mathrm{P}<0.01$ 
Blood glucose level has long been used as indicators of stress in fish. In the present study, serum glucose level in Chlorpyrifos exposed $H$. fossilis increased significantly from their respective control groups. In the Chlorpyrifos exposed fishes, the serum glucose increases with increase of the exposure periods (Table. 2). Increase in blood glucose level may be due to enhanced conversion of liver and muscles glycogen into glucose to meet an increased energy requirement under stress conditions. The depletion of liver glycogen and rise in serum glucose levels was reported in fish as a consequence of water pollution(Srivastava et al., 2012). Under stress condition, hyperglycemia may provide additional energy during time of high metabolic need such as a 'fight or flight' response (Goss and Wood, 1988).From the present investigation, it is clear that the pesticide Chlorpyrifos is very toxic to Heteropneustes fossilis even at sublethal concentration as it has produced adverse effect on the carbohydrate metabolism by elevating the blood glucose level directly interfering with the glucose regulatory mechanism of blood.

Serum protein level reflecting the health condition of any organism and it may changes under the influence of internal and external factors (Srivastava et al., 2012). In the present investigation, serum glucose level increased significantly in Chlorpyrifos exposed $H$. fossilis in comparison to control groups. In the Chlorpyrifos exposed fishes, the serum protein level increases with increase the concentration and time intervals (Table.2). In the present investigation, the increase in serum protein might be due to depletion of tissue protein. Singh and Khare (1999) reported that, protein content in the liver was decreased in pesticide exposed fish, Clarias batrachus. Singh and Sharma (1998) also reported that protein content was increased in blood with decline in liver in insecticides exposed Clarias batrachus. As the liver has multiple metabolic functions, such damage can have serious effects on the metabolism (Srivastava and Prakash, 2019). Thus in the present study, serum protein level was increased due to depletion of protein content in liver. During stress conditions fish need more energy to detoxify the toxicant and to overcome stress. Since fish have fewer amounts of carbohydrates so next alternative source of energy is protein to meet the increased energy demand.

In the present study, triglycerides and cholesterol level were increased significantly in Chlorpyrifos exposed Heteropneustes fossilis in comparisons to control. Triglycerides and cholesterol are known to participate in the rise of total lipid. The elevation of these energy reserves in response to pesticides could be due to the fact that excess energy reserves (glucose, protein, triglyceride and cholesterol)a re required by organisms to mediate the effect of stress (Prakash and Verma, 2018). Since homeostasis of lipid is one of the principal liver functions, any change in serum triglyceride concentration is used as an indicator of liver dysfunction. Srivastava et al, (2012) reported that abnormal accumulation of fats in experimental animals could be due to induced imbalance between fat production and utilization.

In the present investigation, blood urea level increased significantly in Chlorpyrifos exposed $H$. fossilis in comparison to control groups. In the Chlorpyrifos exposed fishes, the blood urea level increases with increase in concentration and duration of exposure. (Table.2). The elevation in the urea level in the in Chlorpyrifos exposed fish may be due to gill dysfunctions as the urea excreted mainly through the gills (Murray et al.,1990). Significant increased levels of urea in heavy metal exposed fishes were the indication of kidney damage (Rashad et al, 2019). Thus it can be concluded that, even at low concentration Chlorpyrifos is highly toxic to catfish.

\section{CONCLUSIONS}

The exposure of Heteropneustesfossilis to sublethal concentration of clorpyrifos for 96 hours showed significant alternation in serum biochemical parameters. This study clearly indicates that the presence of chlorpyrifos in fresh water bodies, even in small concentration, could cause deleterious effects on fish physiology and may potentially disturb their growth, development and survival in the natural environment. It may provide an indication of aquatic pollution load of pesticides in the affected fish population, so help in the diagnosis of the pollution.

\section{ACKNOWLEDGEMENTS}

Author is grateful to Principal and management committee, M.L.K. (P.G) College, Balrampur (U.P.) for providing necessary laboratory facilities.

\section{REFERENCES}

1. Barnes, H., and J. Blackstock. (1973).Estimation of lipids in marine animals and tissues: detailed investigation of the sulphophosphovanilun method for 'total'lipids. Journal of Experimental Marine Biology and Ecology.12(1): 103-118.

2. Bergmeyer, H.U. (1974). Method of Enzymatic analysis vol.2. $2^{\text {nd }}$ Ed. Academic press, New York.p682.

3. Chernyak, S. M., Rice, C.P. and McConnell, L. L. (1996). Evidence of currently-used pesticides in air, 
ice, fog, seawater and surface microlayer in the Bering and Chukchi seas. Marine Poll. Bull. 32(5): 410-419.https://doi.org/10.1016/0025326X(95)00216-A

4. Cox, C. (1994). Chlorpyrifos, part I-III: toxicology, human exposure, ecological effects. J.Pesticide Reform. 14(4): 15-20.

5. Cox, C. (1995). Chlorpyrifos, part I-III: toxicology human exposure, ecological effects. J. Pesticide Reform. 15(1): 14-20.

6. Goss, G.G. and Wood, C.M. (1988).The effects of acid and acid/ aluminum exposure on circulating plasma cortisol levels and other blood parameters in the rainbow trout Salmo gaivdneri. J.Fish Biol.32, 63-76.

7. Grande, M., Anderson, S. and Berge, S. (1994). Effects of pesticides on fish. Norwegian J. Agril. Sci. (Suppl.). 13:195-209.

8. Hoque, M.M., Nahar, Z. and Hossain, M.A. (2000). Toxicity of malathion to silver bar(Barbodes gonionotus Bleeker) fingerlings. Bangladesh J. Fish. Res. 4(1): 101-104.

9. Kadam, P. and Patil, R. (2016). Effect of chlorpyrifos on some biochemical constituents in liver and kidney of fresh water fish, Channa gachua (F.Hamilton).Int. J. Sci. Res. 5(4): 1975-1979.

10. Kaur, G. and Mishra B. K. P. (2019). Histopathological changes in Liver of fish Channa punctatus exposed to sub lethal concentration of Hybrid Pesticide. International Journal of Biological Innovations. 1(2): 83-86. https://doi.org/ 10.46505/IJBI.2019.1209

11. Livingstone, D.R. (2001). Contaminant-stimulated reactive oxygen species production and oxidative damage in aquatic organisms. Bull. Marine Pollutants. 2: 656-666.

12. Klaverkamp, J.F. and Hobden, B.R. (1980). Brain-acetyl cholinesterase inhibition and hepatic activation of acephote and Fenitrothion in rainbow trout (Salmo gairdneri). Canadian Journal of Fisheries and Aquatic Sciences, 37:1450-1453.

13. Mendel, B., Kemp, A. and Mayes, D.K. (1954). A colorimetric micro method for the determination of glucose. Biochem.J.56:639-645.

14. Murray, R.K.D.K., Rranne, P.A.M. and Rodwell, V.W. (1990). Harper's Biochemistry Publisher, Norwalk, Connecticut/ Los Altos, California.
15. Nikam, S.M., Shejule, K.B. and Patil, R.B. (2011). Study of acute toxicity of Metasystox on the freshwater fish, Nemacheilus botia, from Kedrai dam in Maharashtra, India. Biology and Medicine, 3(4): 13-17.

16. Palanikumar, L., Kumaraguru, A.K., Ramakritinan, C.M. and Anand, M. (2014). Toxicity, biochemical and clastogenic response of chlorpyrifos and carbendazim in milkfish Chanos chanos. Int. J. Env. Sci. Tech. 11(3): 765-774.Pathson, C.J. and Nauch, S. R. (1977). Determination of serum urea. Anal. Chem., 49: 464-469.

17. Pathson, C.J. and Nauch, S. R. (1977). Determination of serum urea. Anal. Chem., 49: 464469.

18. Prakash, S. and Verma, A.K. (2014). Effect of Organophosphorus Pesticide(Chlorpyrifos)on the Haematology of Heteropnetues fossilis (Bloch). Int. J. of Fauna \& Biological Studies. 1(5):95-98. .

19. Prakash, S. and Verma, A.K. (2018). Effect of Synthetic detergent on Biochemical constitutions of Freshwater major carp, Labeo rohita. International journal on Agricultural Sciences. 9(1):56-59.

20. Prakash, S. and Verma, A.K. (2019). Acute toxicity and behavioural responses in Arsenic exposed mystus vittatus (Bloch). International Journal on Agricultural Sciences, $10(1): 1-3$.

21. Rashad, E.M. S. Hamdy ,E. H., Mohsen, A. M., Salah, M. E. S., Werner, K. and Alaa, G. M. Osman (2019). Haematological, Serological and Genotoxic Findings in the African Catfish, Clarias gariepinus after the Administration of Copper Nanoparticles and Penconazole. EC Veterinary Science. 4.10: 01-14

22. Sharmin, S., Salam, M.A., Haque, M.A. and Shahjahan, M. (2014). Toxicity bioassay of organophosphorous pesticide malathion in common carp, Cyprinus carpio. pp. 99-100. In: Proc. 5th International Conference on Environmental Aspects of Bangladesh.

23. Siddiqa, A., Islam, M.J., Rahman, M.S., Uddin, M.N. and Fancy, R. (2016). Assessing toxicity of organophosphorus insecticide on local fish species of Bangladesh. Int. J. Fish. Aqu. Stud. 4(3): 670-676.

24. Srivastava, N. and Prakash, S. (2018). Morphological, Behavioural and Haematological alterations in catfish, Clarias batrachus (Linn.) after Acute Zinc Toxicity. International Journal on Biological Sciences. 9(1):72-78. 
25. Srivastava, N. K. and Prakash S. (2019). Effect of Zinc on the Histopathology of Gill, Liver and Kidney of Fresh Water Catfish, Clarias batrachus (Linn.). International Journal of Biological Innovations. 1 (1): 8-13. https://doi.org/10.46505/IJBI.2019.1102.

26. Srivastava, P. Prakash, S. and Ansari, K.K. (2012). Effect of Sodium fluoride on the Blood serum of Heteropneustes fossilis. Biochem. Cell. Arch, 12(2):377-379.

27. Singh, R.K. and Sharma, B. (1998). Carbofuran induced biochemical changes in Clarias batrachus. Pesticide Science: 53 (4):2858-290.

28. Singh, S. and Khare, A. (1999). Effect of pesticide on protein metabolism in liver of Clarias batrachus. Rec. Ad.App.Env. Zool.1:21.

29. Thenmozhi, C., Vignesh, V., Thirumurugan, R. and Arun, S. (2011). Impacts of malathion on mortality and biochemical changes of freshwater fish Labeo rohita. Iranian J. Env. Health Sci. Eng. 8(4): 325-332.

30. Tiwari A., Rastogi A., Singh V. and Arunachalam A. (2019) Water stress effects on nutritional values and relative water content of barnyard and finger millet crops. Int. Agric Sci. 10 (1): 23-28

31. Vasait, J.D. and Patil, V.T., (2005). The toxic evaluation of organophosphorus insecticide monocrotophos on the edible fish species Nemacheilus botia. Ecology Environment and Conservation, 8(1):95-98.

32. Verma, A. K. and Prakash, S. (2018). Haematotoxicity of phorate, an organophosphorous pesticide on a freshwater fish, Channa punctatus (Bloch). International Journal on Agricultural Sciences, 9 (2):117-120.

33. Verma S.R, Rani, S, Bansal S.K, Delala, R.C., (1982). Effect of pesticide thiotox, dichlorovous and chlorofurun on the fish Mystus vittatus. Water, Air and Soil Pollution, 13(2):229-234.

34. Warnick, G.R. (1991). Compact analysis for cholesterol; Triglyceride and high density lipoprotein cholesterol. Curr.Opn.Lpidol.2:343.

35. World Health Organization (2010). The WHO Recommended Classification of Pesticides by Hazard and Guidelines to Classification 2009 (Report). World Health Organization. Retrieved 9 July 2014.

36. Zahan, M.N., Islam, M.J., Mahajebin, T., Rahman, M.S. and Hossain, A.K.M.M. (2019). Toxicity bioassay of chlorpyrifos on some local fish Species of Northern Bangladesh. Int. J. Agril. Res. Innov. Tech. 9(1): 42-47. 